\title{
CARTA DE SUSCEPTIBILIDADE A INFILTRAÇÃO DA ÁGUA NO SOLO NA SUB-BACIA DO RIO MARACANÃ-MA*
}

\author{
INFILTRATION ZONING ON THE GROUND OF MARACANÃ RIVER SUB-BASIN - MA
}

\author{
CARTA DE LA SUSCEPTIBILIDAD A LA INFILTRACIÓN DE AGUA EN EL SUELO \\ DE LA SUB-CUENCA DEL RÍO MARACANÃ-MA
}

José do Nascimento Santos Ediléa Dutra Pereira

\begin{abstract}
Resumo: O estudo do comportamento da infiltração na sub-bacia do Rio Maracanã buscou o entendimento do comportamento da infiltração da água na sub-bacia do Rio Maracanã, onde foram realizados teste de infiltração in situ com infiltrômetro de duplo anel, associado aos conhecimentos geológicos-geotécnicos da área que subsidiou a elaboração da Carta de susceptibilidade a infiltração da água no solo da sub-bacia do Rio Maracanã utilizando o método de krigagem. As áreas de recarga estão severamente impactadas com baixa susceptibilidade à infiltração em decorrência do intensivo uso e ocupação. Esse comportamento paulatinamente atinge severamente a biodiversidade local. A melhoria da qualidade de vida na sub-bacia do Rio Maracanã depende de um planejamento municipal, principalmente no uso e ocupação do solo e das diversas atividades humanas realizadas na área.
\end{abstract}

Palavras-chave: Infiltração. Recarga de aquífero. Sub-bacia do Rio Maracanã.

\begin{abstract}
The main aims of this work (This report or) was studied the infiltration behavior of the Rio Maracanã sub-basin in order to understand the water infiltration behavior. Infiltration tests were performed in situ with double ring infiltrometer, combined with geologic and geotechnical information that supported the drafting susceptibility to water infiltration of the area and soil of the sub-basin using the kriging method. The aquifer recharge areas are severely impacted with low susceptibility to infiltration due to intensive human use and occupation. This behavior gradually affects local biodiversity. To improving the quality of life at the Rio Maracanã sub-basin its necessary a municipal planning specially focused in the human occupation and use of land in several activities.
\end{abstract}

Keywords: Infiltration. Aquifer recharge. Sub-basin of Maracanâ River

Resumen: El estudio del comportamiento de la infiltración en la subcuenca del Río Maracanã trató de comprender el comportamiento de la infiltración del agua en la subcuenca del Rio Maracaná, donde se realizó el ensayo de infiltración in situ con infiltrómetro de doble anillo, combinado con conocimientos geológicos y geotécnicos de la área que apoyó la redacción de la Carta de la susceptibilidad a la infiltración de agua en el suelo de la sub-cuenca del Río Maracanã utilizando el método de kriging. Las áreas de recarga se ven muy afectadas con la baja susceptibilidad a la infiltración debido a un uso intensivo y la ocupación. Este comportamiento gradualmente afecta gravemente a la biodiversidad local. La mejora de la calidad de vida en la subcuenca del Río Maracanã depende de una planificación municipal, especialmente en el uso y ocupación del suelo y las diversas actividades realizadas en la zona.

Palabras clave: Infiltración. Recarga de los acuíferos. Sub-cuenca del Rio Maracanã.

\section{INTRODUÇÃO}

Os corpos hídricos na superfície terrestre são indispensáveis para os seres humanos, pois estes necessitam para desenvolver suas atividades necessárias à sua sobrevivência, a exemplo: consumo humano, indústrias, geração de energia elétrica, agricultura, irrigação, dentre outros.

Em geral, os recursos naturais utilizados pelas sociedades humanas são finitos. A qualidade da água torna-se finita devido às práticas humanas inadequadas de extração, consumo e poluição deste precioso recurso natural. A grande questão da atualidade é o comprometimento futuro da sua qualidade, pois a água tem alta vulnerabilidade à contaminação e corre sérios riscos considerando o desenvolvimento sócioeconômico da sociedade.

A partir da década de 1970, a Ilha do Maranhão vem sofrendo diversas transformações no seu espaço geográfico, devido à chegada de grandes empreendimentos, estes ocupando áreas de preservação ambiental e consequentemente compactando os solos, desmatando a vegetação nativa e aterrando as diversas nascentes.

Trabalho premiado durante o XXIV Encontro do SEMIC, realizado na UFMA entre os dias 05 a 08 de novembro de 2012.

*Artigo recebido em dezembro 2012

Aprovado em fevereiro 2013 
Neste contexto, a infiltração de água no solo torna-se de fundamental importância para a análise das recargas dos aquíferos e a manutenção do equilíbrio da cunha salina em regiões costeiras, considerando que o Município de São Luís está localizado em uma ilha, onde os recursos hídricos sofrem sérios riscos de contaminação.

Nesta perspectiva, este trabalho objetivou elaborar a carta de infiltração de água no solo a partir dos testes de infiltração da água para subsidiar estudos de planejamento e gestão na sub-bacia do Rio Maracanã, a fim de fornecer dados e/ou informações que possam atenuar os possíveis impactos ambientais existentes e contribuir para a recuperação das áreas impactadas. Esta pesquisa foi desenvolvida com o apoio da bolsa de pesquisa PIBIC-UFMA no âmbito do Projeto Recuperação das áreas degradadas de recarga e descarga do Aquífero Barreiras da sub-bacia do Rio Maracanã, convênio CNPQ/UFMA, no laboratório de Estudos de Bacias (LEBAC).

A sub-bacia do Rio Maracanã é onde são encontradas as principais nascentes do Rio Bacanga, localizada no bairro Maracanã, área rural do Município de São Luís-MA. Trata-se de uma área de recarga de aquífero que abriga algumas nascentes permanentes, consideradas estratégicas para a conservação e preservação da água doce na Ilha do Maranhão. Está situada entre as coordenadas Universal Transverse de Mercator (Projeção UTM), fuso 23S; N 9706000 / 9713000m e E 577000 / 584000 m (Figura 1).

Figura 1- Localização geográfica da sub-bacia do Rio Maracanã-MA

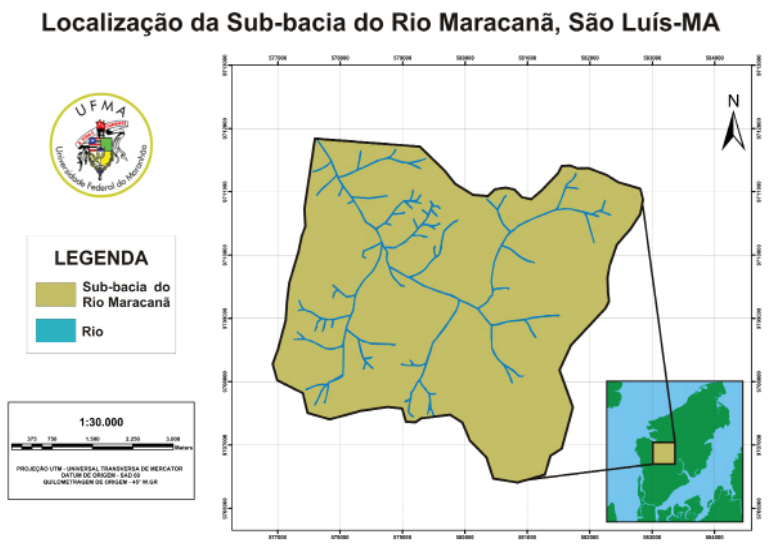

Fonte: Cavalcanti Junior (2011)

O acesso à área da sub-bacia é realizado por meio das bifurcações da BR-135, lado leste, através das vias de acesso às comunidades do entorno do Distrito Industrial de São Luís; e lado oeste, através da via de acesso da Vila Maranhão.

\section{MATERIAIS E MÉTODO}

A composição da base cartográfica do trabalho foi elaborada com o auxílio das cartas planialtimétrica do Ministério do Exército/ Diretoria de Serviço Geográfico (DSG) nas Folhas 30, 31, 38 e 39 de 1980 na escala 1:10.000 (MINISTÉRIO DO EXÉRCITO, 1980) e o reconhecimento da área foi realizado através de sucessivos trabalhos de campo com base nas observações e integrações das características geológicas e geomorfológicas, das feições e elementos de relevo, dos tipos de solo, uso e ocupação e atividades econômicas, extraídos de Rodrigues et al. (1994), Maranhão (1998) e Pereira (2006). Para o georeferenciamento utilizou-se o aparelho GPS - Garmin Plus e o registro fotográfico pela câmera fotográfica de alta resolução tipo Sony 14 pixels. Foram realizados 02 testes de infiltração com infiltrômetro de duplo anel na área da pesquisa, associados aos 11 testes realizados previamente por Cavalcanti Júnior (2011). Todas as análises foram feitas no período de estiagem nas áreas do topo, encosta e base de colina, associadas às observações da cobertura pedológica, litológica, espessura, uso do solo e os registros dos processos e problemas ambientais.

Os 13 dados de infiltrações foram interpolados pelo método de Krigagem utilizando Sistemas de Informação Geográfica que gerou a, Carta de Susceptibilidade a Infiltração de Água no Solo cuja análise foi correlacionada a Carta de uso e ocupação do solo na sub-bacia do Rio Maracanã.

\section{INFILTRAÇÃO DE ÁGUA NO SOLO}

A infiltração é um processo integrante da fase subterrânea do ciclo hidrológico. O processo de infiltração inicia-se quando a água da chuva ou de irrigação atinge a superfície terrestre. A infiltrabilidade do solo é a máxima razão na qual a chuva ou água de irrigação podem ser absorvidas pelo subsolo sob determinada condição. O conhecimento das taxas de infiltrabilidade possibilita estimar a quantidade de água disponível para infiltração e escoamento superficial em uma determinada área.

A infiltração no solo pode ser influenciada pela precipitação, composição mineralógica, textura, cobertura vegetal, matéria orgânica, relevo e ocupação do solo conforme Brandão, Pruski e Silva (2002). A precipitação é um dos fatores preponderantes, no que diz respeito ao volume de recarga dos aquíferos nas bacias hidrográficas, e destaca a textura e a estrutura como as características determinantes na movimentação da água no solo uma vez que determina a quantidade, disposição geométrica e volumétrica dos macro poros no perfil dos solos. Assim, geralmente solos arenosos possuem elevadas taxas de infiltração que os solos de textura fina.

A forma do relevo pode influenciar nas taxas de infiltração, pois regiões de topografias planas ou relativamente planas absorvem a maior parte das águas precipitadas sobre o solo, resultando em menores volumes de água para o escoamento superficial. 
A cobertura vegetal é de fundamental importância no processo de recepção da água precipitada sobre o solo. A interceptação é feita através da copa das árvores, serrapilheira e das gramíneas. No caso de mata muito densa o escoamento se dá pelas laterais do tronco e pelas folhas chegando de maneira suave ao solo.

A matéria orgânica incorporada ao solo permite maior agregação e coesão entre as partículas, tornando o solo mais poroso e com maior poder de retenção de água, favorecendo o aumento de sua capacidade de infiltração.

As formas de ocupação do solo podem trazer sérios problemas de ordem socioambiental como a compactação dos solos interferindo diretamente na diminuição da infiltração e consequentemente nas recargas de aquíferos.

A quantidade de água absorvida pelo solo chega a um limite quando este não admite mais espaços abertos (poros), formando assim o nível de água subterrânea ou superfície freática (Figura 2).

Figura 2 - Distribuição de água no subsolo

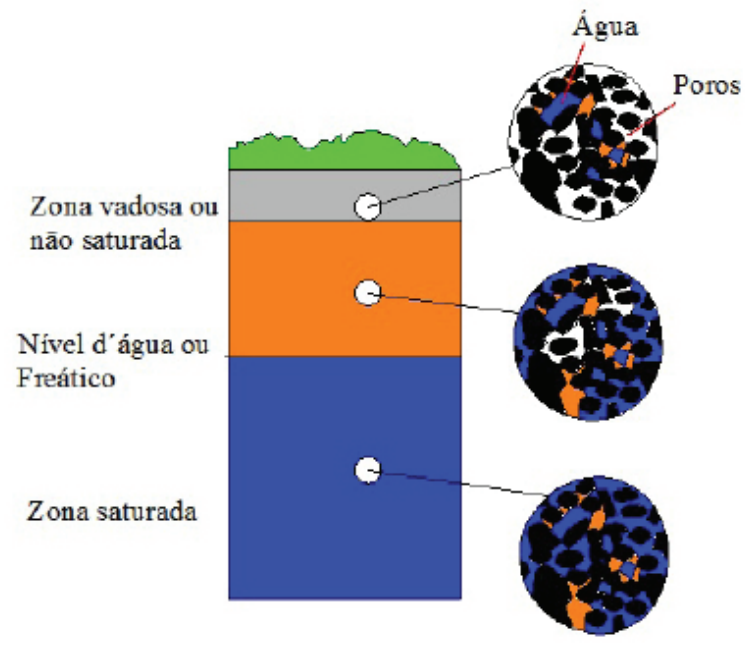

Fonte: Pereira (2006), adaptado de Karmann (2003).

No início do processo de infiltração as primeiras taxas, em geral, são altas, contudo as demais tendem a um decréscimo no volume de infiltração, assim se estabilizando e chegando ao valor da condutividade hidráulica do solo saturado (Figura 3).

Figura 3- Evolução da taxa de infiltração com o tempo

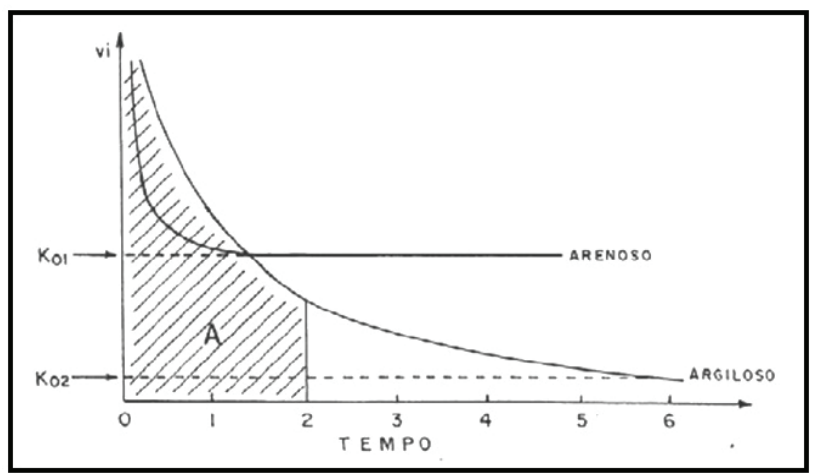

Fonte: Reichardt (1990).
Depois que esta água infiltra no solo, este se torna úmido e apresenta pequena quantidade de ar nos poros. Os microporos presentes no solo são tubos muito finos e também recebem o nome de capilares e o líquido nele contido é chamado de água capilar, conforme Lepsch (2002). A permeabilidade (K) do solo está relacionada diretamente com a estrutura deste, bem como a captação desse líquido, portanto, a capacidade de retenção líquida do terreno será analisada a partir de suas estruturas pedológicas.

O estudo aprofundado da interação água e solo permite compreender que as modificações na estrutura pedológica e o mau uso e ocupação do terreno podem ocasionar na área diminuição da infiltração da água no solo e um severo impacto nas reservas de água subterrânea e na biodiversidade.

\section{INFILTRÔMETRO DE DUPLO ANEL}

O método infiltrômetro de duplo anel, conforme Reichardt (1990), consiste na utilização de dois cilindros concêntricos de 60 e $30 \mathrm{~cm}$ de diâmetro. A função do cilindro externo é de atenuar o efeito da histerese no solo e garantir um fluxo vertical no cilindro interno (Foto 1 ).

A permeabilidade $(K)$ é o coeficiente que expressa a facilidade com que um fluido é transportado através de um meio poroso e depende das propriedades do meio e do fluido, conforme Libardi (1980) e Cedergren (1989).

Foto 1 - Materiais utilizados no ensaio de infiltração com infiltrômetro de duplo anel

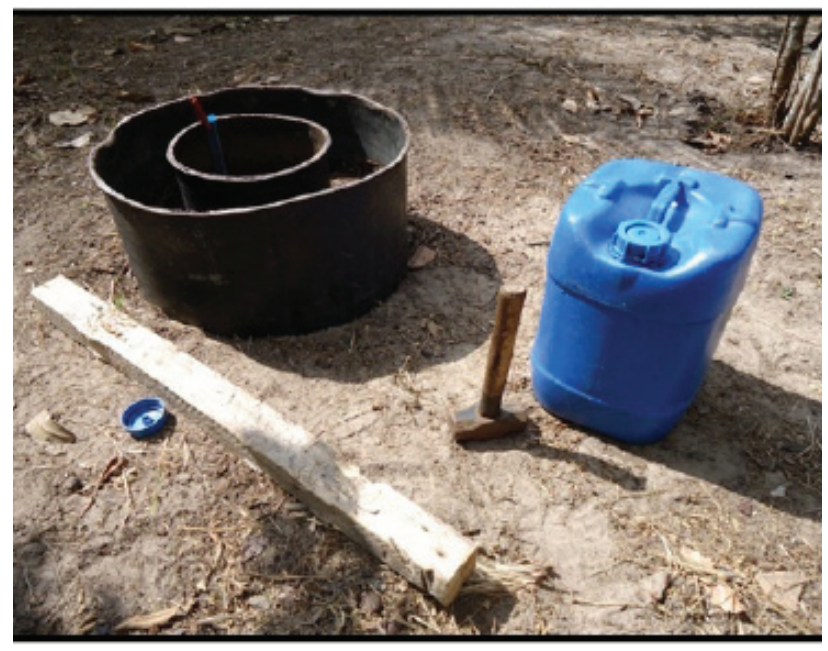

Fonte: Pereira (2012)

Pode-se determinar a velocidade de infiltração (Vi) para cada instante, considerando os tempos $(\Delta \mathrm{t})$ e os valores de altura $(\Delta \mathrm{h})$, valores estes que são medidos por meio de uma régua fixa no cilindro interno, que indica a altura de água sobre o solo. A velocidade de infiltração (Vi) é expressa pela seguinte equação, conforme Reichardt (1990): 


$$
V i=\frac{\Delta h}{\Delta t} \times 60=\frac{h_{n}-h_{n-1}}{t_{n}-t_{n-1}} \times 60
$$

$O$ resultante da infiltração acumulada $(\Delta \mathrm{h})$ versus tempo $(\Delta \mathrm{t})$ indica as medidas de $\mathrm{Vi}$, alta no início da infiltração e diminuindo com o passar do tempo. O solo se satura e a velocidade de infiltração se estabiliza, assumindo um valor constante, denominado permeabilidade do solo saturado (K), (Tabela 1 ).

Tabela 1- Critério de classificação de infiltração básica

\begin{tabular}{l|l}
\hline \multicolumn{1}{c|}{ K } & \multicolumn{1}{c}{ VALOR $(\mathbf{c m} / \mathbf{h})$} \\
\hline Muito alto & $>3$ \\
Alto & $1,5-3$ \\
Médio & $0,5-1,5$ \\
Baixo & $0,1-0,5$ \\
Muito baixo & $<0,1$ \\
& \\
\hline
\end{tabular}

Fonte: Reichardt (1990)

A equação utilizada para calcular o valor da permeabilidade do solo saturado $(K)$ foi a proposta por Radcliffe e Simunek (2010) associada aos critérios de classificação de $\mathrm{K}$ de Reichardt (1990), portanto:

$$
K=\frac{I s}{1+\frac{4 . \lambda c}{\pi \cdot r}}
$$

Onde:

$K$ : permeabilidade do solo saturado;

Is: infiltração estável;

$\lambda \chi$ : comprimento da capilaridade macroscópica do solo conforme as categorias de

textura e estrutura;

$\pi: 3,14$;

$\mathrm{r}$ : raio do anel.

O valor do comprimento da capilaridade macroscópica do solo, conforme as categorias de textura e estrutura $(\lambda c)$, é encontrado na Tabela 02, conforme Elrick e Reynols (1992 apud RADCLIFFE; SIMUNEK, 2010).

Na área da sub-bacia do Rio Maracanã os solos apresentaram textura areno-argilosa, argilo-arenosa a argilosa, moderadamente estruturado, portanto o valor adotado será de 8,3 para estimação do comprimento da capilaridade macroscópica do solo, conforme as categorias de textura e estrutura $(\lambda c)$ no cálculo da permeabilidade.

As vantagens e desvantagens do método infiltrômetro de duplo anel:

a) o aparelho é barato e de fácil operacionalização;

b) no campo, o ensaio pode ser realizado por 2 ou 3 pessoas; . c) O tempo de operacionalização é menor comparado com outros métodos;

d) há necessidade de grande quantidade de água para realização do ensaio;

e) o tamanho dos infiltrômetros dificulta o transporte em alguns casos, principalmente em mata fechada ou de difícil acesso;

f) o infiltrômetro pode operar somente na área superficial do solo e em terrenos de declividade plana a suavemente moderada;

g) em solos intensamente laterizados ou compactados requer maior aplicação de força para encravamento.

Tabela 2 - Valores de estimação do comprimento da capilaridade macroscópica do solo para as categorias de textura e estrutura $(\lambda c)$, Elrick e Reynolds (1992 apud RADCLIFFE; SIMUNEK, 2010).

\begin{tabular}{l|l}
\hline $\begin{array}{l}\text { Estimação do comprimento da } \\
\text { capilaridade macroscópica do solo } \\
\text { conforme as categorias de textura e } \\
\text { estrutura }(\lambda c)\end{array}$ & $\lambda c(\mathbf{c m})$ \\
\hline $\begin{array}{l}\text { Sedimentos grosseiros, cascalhos, areia, } \\
\text { podendo incluir solos altamente estrutu- } \\
\text { rados com grande quantidade de macro- } \\
\text { poros e fissuras. }\end{array}$ & 2,8 \\
\hline $\begin{array}{l}\text { Solos mais estruturados a partir de argi- } \\
\text { las e loam também incluem solos mode- } \\
\text { radamente estruturados e areia fina. }\end{array}$ & 8,3 \\
\hline $\begin{array}{l}\text { Solos com textura fina (argiloso) e não } \\
\text { estruturado. }\end{array}$ & 25 \\
\hline $\begin{array}{l}\text { Solos compactados não estruturados, } \\
\text { material argiloso como capas de landfill e } \\
\text { liners, lacustrino ou sedimentos marinhos } \\
\text { etc. }\end{array}$ & 100 \\
\hline
\end{tabular}

Fonte: Elrick e Reynolds (1992 apud RADCLIFFE; SIMUNEK, 2010)

\section{FISIOGRAFIA DA SUB-BACIA DO RIO MARACANÃ}

A sedimentação na Bacia de São Luís iniciou-se com os sedimentos do Cretáceo da Formação Itapecuru, Formação Terciário-Paleogeno, Formação Barreiras e, finalmente, pelos sedimentos recentes da Formação Açuí, conforme Rodrigues et al. (1994).

$\mathrm{Na}$ área da sub-bacia do Rio Maracanã as litologias presentes pertencem predominantemente à Formação Barreiras e Formação Açuí (Quadro 1).

Os sedimentos terciários da Formação Barreiras são areno-argilosos de coloração róseo-avermelhada, siltitos maciços de cores amarela a ocre, ferruginados e, ocasionalmente, conglomeráticos, desorganizados. Apresentam um perfil imaturo, com sedimentos inconsolidados, argilosos, com areias disseminadas, amarelados a avermelhados, com 
nódulos e blocos de concreções ferruginosas (RODRIGUES et al., 1994).

A Formação Açuí é composta por sedimentos quaternários areno-argiloso inconsolidados; argilosos não adensados e de mangue preenchendo as partes de topografia mais baixa e pelas areias de praia e das dunas móveis da faixa litorânea atual, conforme Rodrigues et al. (1994).

A Ilha do Maranhão está situada no centro da Planície Flúvio-Marinha do Golfão Maranhense, conforme Ab'Saber (1960). Na ilha são encontradas as mais variadas formas de relevo característicos do Estado do Maranhão, pois apresenta nas faixas de baixas altitudes, 0 a 5 metros, as planícies flúvio-marinhas formadas pelos extensivos mangues e nos níveis de 20 a 30 metros as suaves colinas dissecadas, nas altitudes maiores de 40 a 60 metros têm-se a presença das superfícies planas dos tabuleiros geralmente dissecados, conforme Pereira (2006).

Quadro 1 - Coluna estratigráfica da Ilha do Maranhão-MA

\begin{tabular}{|c|c|c|c|c|c|}
\hline \multicolumn{3}{|c|}{$\begin{array}{l}\text { ERA } \\
\text { PERIODO }\end{array}$} & $\begin{array}{l}\text { Unidades } \\
\text { estratigráfica }\end{array}$ & Litologia & $\begin{array}{l}\text { Potencial } \\
\text { Mineral }\end{array}$ \\
\hline \multirow{3}{*}{ : } & 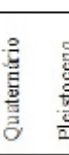 & 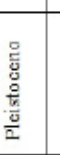 & $\begin{array}{l}\text { FORMAÇÃO } \\
\text { AÇUI }\end{array}$ & 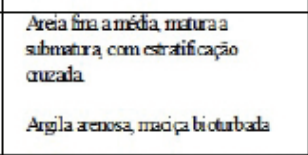 & $\begin{array}{l}\text { Areia } \\
\text { Arcia } \\
\text { Argila }\end{array}$ \\
\hline & & 总 & $\begin{array}{l}\text { FORMAC̣̃O } \\
\text { BARRHRAS }\end{array}$ & 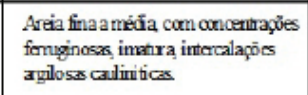 & $\begin{array}{l}\text { Argla } \\
\text { Aççara }\end{array}$ \\
\hline & 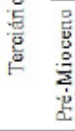 & 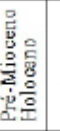 & $\begin{array}{l}\text { TFRCIARIO } \\
\text { PALEOGENO }\end{array}$ & 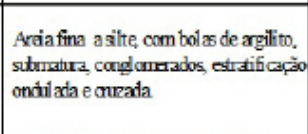 & $\begin{array}{l}\text { Areja } \\
\text { Piçara } \\
\text { Argla }\end{array}$ \\
\hline & \multirow{2}{*}{\multicolumn{2}{|c|}{ 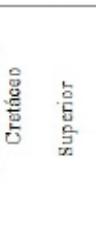 }} & 롴 MembroAlcântara & 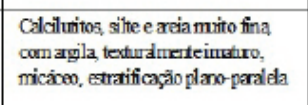 & $\begin{array}{l}\text { Cácaio } \\
\text { Angila }\end{array}$ \\
\hline & & & MembroPsamítico & 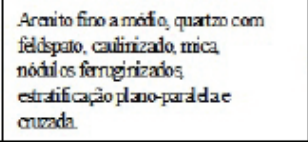 & Água schtarânea \\
\hline
\end{tabular}

Fonte: Rodrigues et al., (1994).

A maior altitude encontrada na ilha atinge os 60 metros (Tabela 3). Os tabuleiros dissecados e as colinas da Sub-bacia do Rio Maracanã geralmente formam os divisores de água dos afluentes e subafluentes. As planícies fluviais são formações mais recentes com agradação avançada.

Existe uma carência de estudos que enfoque a geomorfologia da área. Destacamse os trabalhos de Ab'Saber (1960), Barbosa e Pinto (1973) através do projeto RADAM, Pereira (2006) e Silva (2012).

A Ilha do Maranhão se insere na área de transição climática do semi-árido nordestino e tropical úmido amazônico, considerado como um clima tropical chuvoso, com estação seca de inverno, tipo Aw, conforme a classificação de Köppen (STRAHLER, 1960).

As temperaturas médias variam ao longo do ano entre 25,5 e $28,5^{\circ} \mathrm{C}$. Observa-se que as temperaturas mais elevadas ocorrem entre agosto a novembro chegando a atingir aproximadamente $31^{\circ} \mathrm{C}$, conforme Universidade Federal do Maranhão (2009).

As direções predominantes dos ventos são nas direções NE e E ao longo de todo o ano, com velocidades mais elevadas nos meses secos, quando as médias mensais se situam em torno de $7 \mathrm{~m} / \mathrm{s}$. A umidade média anual do ar é em torno de $80 \%$.

Nota-se que nestes últimos nove anos analisados a média anual de pluviosidade no município de São Luís atingiu valor de $1.882 \mathrm{~mm}$ (Figura 4). Segundo os dados pluviométricos do Laboratório de Meteorologia de São Luís - NUGEO foram registrados até outubro de 2011 um volume total de chuvas de $2.376 \mathrm{~mm}$. O mês de abril foi o mais chuvoso com $484 \mathrm{~mm}$ registrados, considerado um ano excepcionalmente chuvoso. O mês de setembro foi o mês que não choveu, sendo realizados neste período os testes de infiltração na subbacia do Rio Maracanã.

Os solos presentes na área, conforme Empresa Brasileira de Pesquisa Agrapecuária (1986), foram o latossolo e o gleissolos. O latossolo encontra-se ao longo de topos tabuleiros e colinas cujo relevo é plano com pequenas e suaves ondulações, de textura fina a média, derivados dos sedimentos da Formação Barreiras. Os gleissolos formam-se nas áreas úmidas rica em matéria orgânica encontrados nas áreas de várzeas do Rio Maracanã e seus afluentes.

A sub-bacia do Rio Maracanã abriga as nascentes do Rio Bacanga $\left(106 \mathrm{Km}^{2}\right.$ ). Trata-se de uma área rural em que se encontram inúmeras nascentes de permanência estratégica para conservação e preservação da água doce na Ilha do Maranhão.

A sub-bacia do Rio Maracanã apresenta uma área de $21 \mathrm{~km}^{2}$, perímetro de 19,8 km e comprimento máximo de $6,4 \mathrm{~km}$, com padrão

Tabela 3- Compartimentação do relevo da Sub-bacia do Rio Maracanã-MA.

\begin{tabular}{c|c|c}
\hline $\begin{array}{c}\text { DOMÍNIO } \\
\text { MORFOESTRUTURAL }\end{array}$ & $\begin{array}{c}\text { UNIDADE } \\
\text { GEOMORFOLÓGICA }\end{array}$ & $\begin{array}{c}\text { SUBUNIDADES } \\
\text { LOCAIS DO RELEVO }\end{array}$ \\
\hline $\begin{array}{c}\text { Bacia Costeira de São } \\
\text { Luís. }\end{array}$ & $\begin{array}{c}\text { Planície Flúvio-marinha do Golfão Ma- } \\
\text { ranhense. }\end{array}$ & $\begin{array}{c}\text { Tabuleiros, colinas dissecadas, planícies fluviais e } \\
\text { flúvio-marinhas. }\end{array}$ \\
\hline
\end{tabular}

Fonte: Pereira (2012) 
de drenagem dendrítica, $4^{a}$ ordem, conforme Strahler (1960) e Cysne (2011).

Figura 4 - Altura pluviométrica do ano de 2011

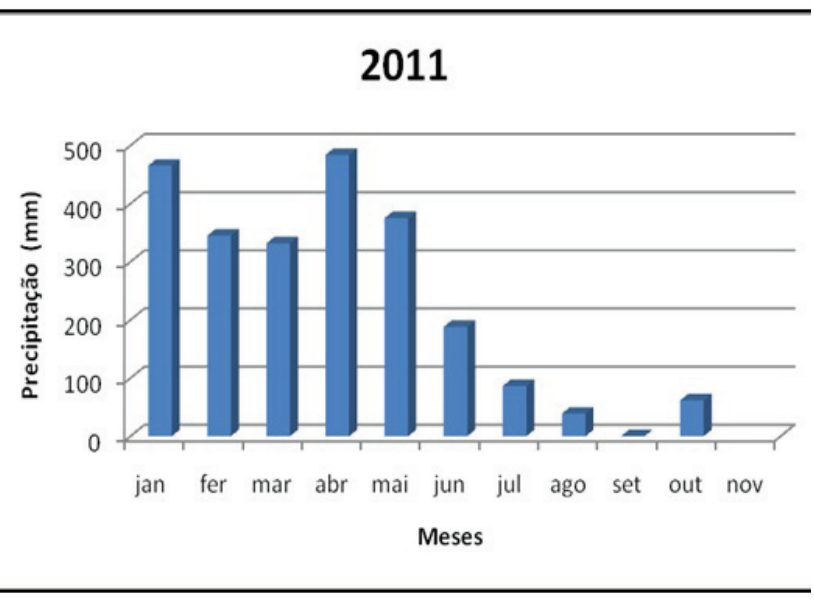

Fonte: (NUGEO, 2011; INSTITUTO NACIONAL DE METEOROLOGIA, 2011).

Na área de influência da Sub-bacia do Rio Maracanã, a vegetação predominante é a de mata perenifólia de várzea, com destaque para as palmáceas juçara e buriti (OLIVEIRA, 2003). Este tipo de vegetação se concentra nas áreas mais baixas da rede de drenagem, nas áreas mais altas a cobertura vegetal é composta de capoeiras e babaçuais. No final do baixo curso da sub-bacia ocorre uma pequena faixa de ocorrência de vegetação de mangue.

\section{INFILTRAÇÃO NA SUB-BACIA DO RIO MARACANÃ}

Os testes de infiltração indicam uma tendência de valor de infiltração, considerando que a permeabilidade é muito variável e depende das propriedades geotécnicas do terreno como textura, estrutura, porosidade, relevo, vegetação e o uso e ocupação do solo.

\subsection{Topo e alta encosta dos tabuleiros e colinas dissecados}

Na Sub-bacia do Rio Maracanã os topos, alta encosta dos tabuleiros e colinas dissecados compõem-se de sedimentos no horizonte "A" de coloração $5 Y$ 7/2 (cinza-claro) a (bruno - amarelado) 10YR 6/4, arenoso com presença de lateritas de forma dispersa.

$\mathrm{Na}$ unidade do topo e alta encosta do tabuleiro foram realizadas 09 análises in situ de testes de infiltrações pelo método infiltrômetro de duplo anel (Tabela 4).

Os principais problemas ambientais que ocorrem nesta unidade de relevo são os frequentes estresses pela ocupação de suas áreas e intensos desmatamentos, principalmente para construções de casas, estradas, indústrias, selamentos do solo e impermeabilizações.
Tabela 4 - Valores de permeabilidade do topo e a alta encosta dos tabuleiros e colinas

\begin{tabular}{c|c|c}
\hline Amostras & $\begin{array}{c}\text { Permeabilidade } \\
(\mathbf{K}) \mathbf{~ c m} / \mathbf{h}\end{array}$ & $\begin{array}{c}\text { Classificação de } \\
\text { Reichardt } \\
(\mathbf{1 9 9 0})\end{array}$ \\
\hline I -1 & 0,11 & baixa \\
\hline I-2 & 0,11 & baixa \\
\hline I-3 & 0,11 & baixa \\
\hline I-4 & 0,35 & baixa \\
\hline I-5 & 0,23 & baixa \\
\hline I-6 & 0,64 & média \\
\hline I-7 & 0,70 & média \\
\hline I-8 & 1,17 & média \\
\hline I-9 & 0,11 & média \\
\hline
\end{tabular}

Fonte: Pereira (2012).

\subsection{Média a baixa encosta das colinas dissecadas}

As encostas dos tabuleiros e colinas dissecadas apresentaram no horizonte " $\mathrm{A}$ " coloração variável de $5 Y$ 7/2 (cinza-claro) a 2,5YR $6 / 4$ (bruno-avermelhado claro) com granulometria indicando solo arenoso. Os depósitos aluvionares ocorrem nas áreas de várzeas do Rio Maracanã e seus afluentes, com altitudes inferiores a 20 metros, onde predominam as águas doces. Apresentam sedimentos inconsolidados retrabalhados provenientes das áreas altas, pertencentes à Formação Barreiras.

Na porção norte, noroeste e sudoeste das encostas das colinas da sub-bacia do Rio Maracanã foram realizados 04 testes de infiltração (Tabela 5) que indicaram permeabilidade variável de baixa a alta.

Tabela 5 - Valores de permeabilidade da média e baixa encosta das colinas

\begin{tabular}{c|c|c}
\hline Amostras & $\begin{array}{c}\text { Permeabilidade } \\
(\mathbf{K}) \mathbf{~ c m} / \mathbf{h}\end{array}$ & $\begin{array}{c}\text { Classificação } \\
\text { de Reichardt } \\
\mathbf{( 1 9 9 0 )}\end{array}$ \\
\hline $\mathrm{I}-10$ & 0,11 & Baixa \\
\hline $\mathrm{I}-11$ & 1,35 & Média \\
\hline $\mathrm{I}-12^{*}$ & 0,71 & Média \\
\hline $\mathrm{I}-13 *$ & 3,0 & Alta \\
\hline
\end{tabular}

Fonte: Pereira (2012)

\subsection{Ensaios realizados neste estudo}

No início do ensaio I-12 a infiltração atingiu uma velocidade de $66 \mathrm{~cm} / \mathrm{h}$ e alcançou uma relativa estabilidade a partir de 0,60 horas de experimento. $O$ volume acumulado no ensaio de infiltração foi de 9,25 litros em aproximadamente 1.20 horas de experimento (Figuras 5 e 6 ).

No início do ensaio I-13 a velocidade de infiltração atingiu uma velocidade de $84 \mathrm{~cm} / \mathrm{h}$ e alcançou uma relativa estabilidade a partir de 0,60 horas de experimento. 0 volume acumu- 
lado no ensaio de infiltração obteve valor de 21,27 litros em aproximadamente 1,20 horas de experimento (Figuras 7 e 8 ).

Figura 5 - Curva de velocidade de infiltração na média encosta da colina

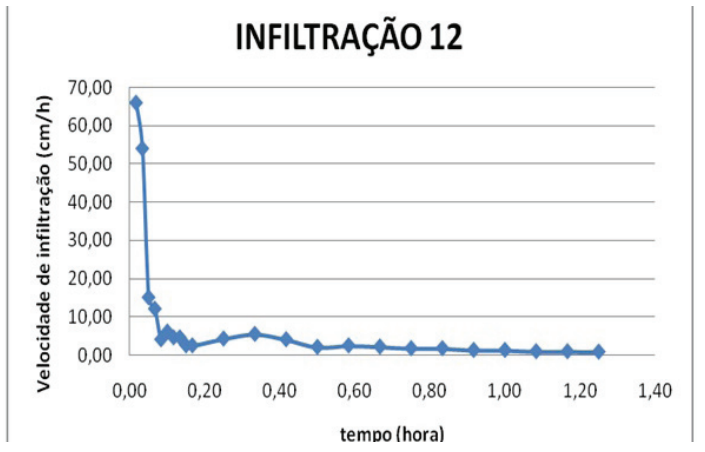

Fonte: Dados da pesquisa (2012)

Figura 6 - Curva do volume acumulado de infiltração na média encosta da colina

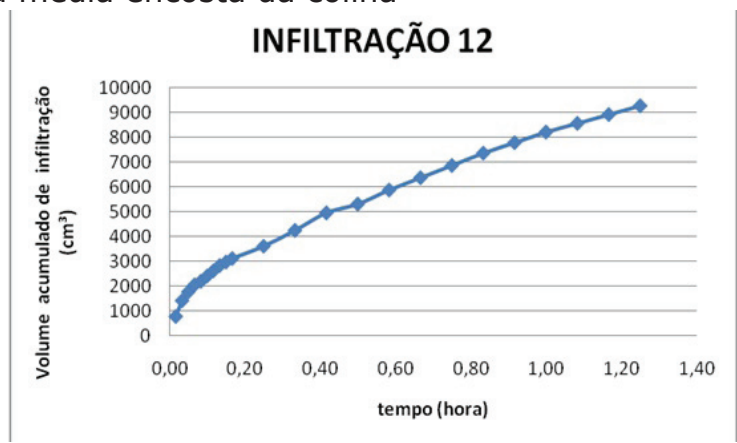

Fonte: Dados da pesquisa (2012)

Figura 7 - Curva de velocidade de infiltração na baixa encosta da colina

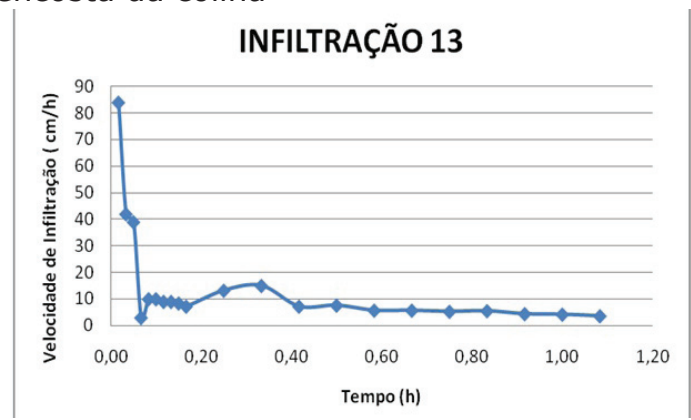

Fonte: Dados da pesquisa (2012)

Figura 8 - Curva do volume acumulado infiltração na baixa encosta da colina

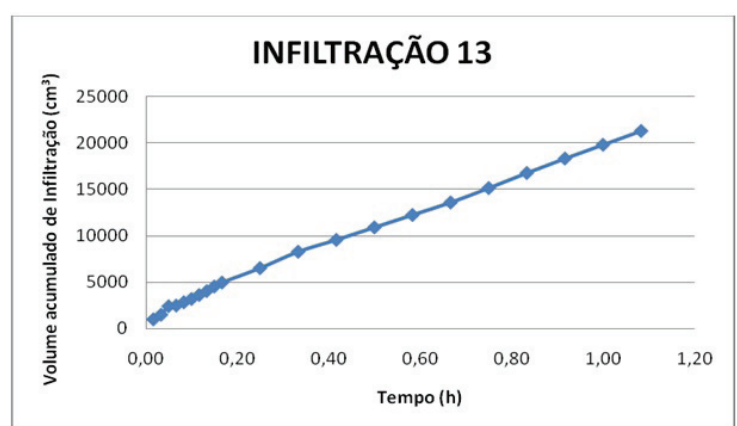

Fonte: Dados da pesquisa (2012)
Os principais problemas ambientais que ocorrem nesta unidade são os intensivos desmatamentos com a retirada da juçara e outras espécies nativas, ocupações espontâneas, inundação e plantio de culturas perenes e temporárias.

A carta de susceptibilidade a infiltração de água no solo elaborada a partir de 13 pontos de inflitrações pelo método de krigagem indicou uma susceptibilidade baixa na porção sul e sudeste da sub-bacia e média a alta na porção norte, noroeste e sudoeste da área. Nessas zonas encontram-se vegetação arbórea, arbustiva e herbácea que facilita a infiltração da água (Figuras 9 e 10).

Figura 9 - Carta de susceptibilidade a infiltração de água na sub-bacia do Rio Maracanã-MA

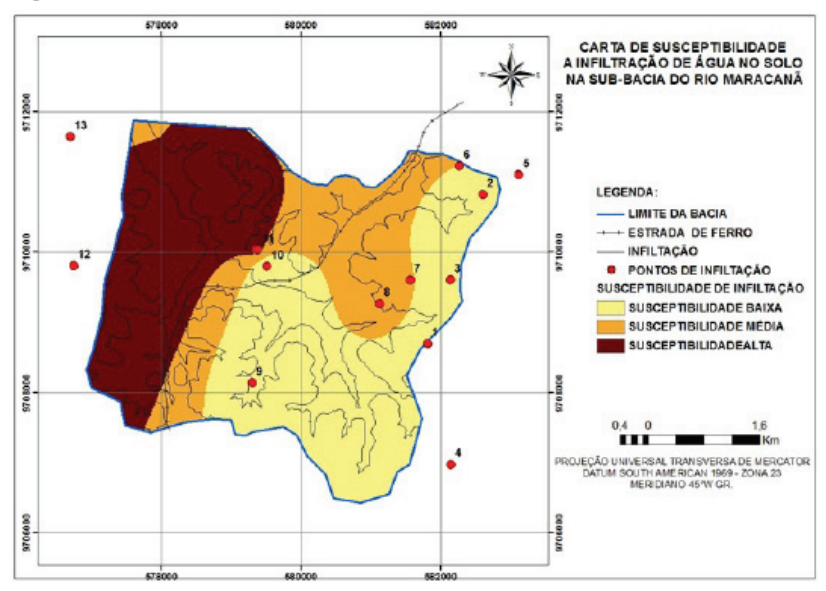

Fonte: Dados da pesquisa (2012)

Figura 10 - Carta de uso e ocupação da sub-bacia do Rio Maracanã-MA

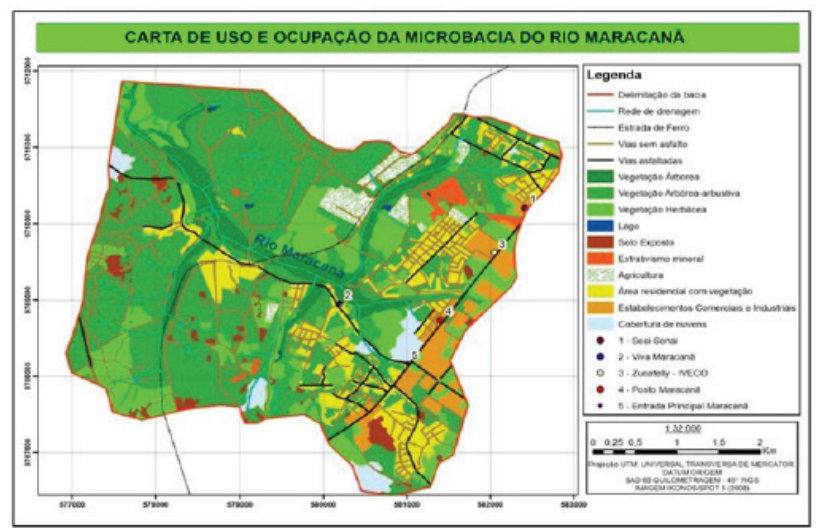

Fonte: Cysney (2011)

\section{CONSIDERAÇÕES FINAIS}

Este estudo buscou o conhecimento do comportamento da infiltração da água na subbacia do Rio Maracanã, onde foram realizados testes de infiltração in situ com infiltrômetro de duplo anel, associado aos conhecimentos geológicos-geotécnicos da área que subsidiou a elaboração da Carta de susceptibilidade à infiltração da água no solo da sub-bacia do Rio Maracanã.

A porção sudeste e este da sub-bacia do Rio Maracanã apresentou susceptibilidade 
baixa à infiltração em decorrência dos severos impactos ocasionados pelo uso e ocupação sem prévio planejamento e observância das vulnerabilidades e potencialidades das características do terreno. As áreas de tabuleiros consideradas áreas de recarga do aquífero Barreiras e Itapecuru nesta área não exercem suas funções ecológicas. O intensivo uso e ocupação ao longo da BR-316, associada às impermeabilizações e selamento do terreno são as possíveis causas.

Na porção norte e oeste da sub-bacia do Rio Maracanã obteve-se uma permeabilidade de média a alta. Nestas áreas têm-se uma vegetação arbórea-arbustiva e herbácea onde se encontram os ecossistemas de várzeas, destacando-se a presença das matas ciliares e dos frondosos juçarais e buritizais ainda presentes na área.

Acredita-se que a utilização das sub-bacias hidrográficas como unidade de planejamento ambiental é uma decisão acertada, pois possibilita o estudo pormenorizado dos impactos ambientais oriundos da ação antrópica de forma indiscriminada.

São relevantes estudos e medidas que orientem a ocupação humana, respeitando as fragilidades e as potencialidades ambientais para demonstrar que é possível o homem ocupar o espaço e progredir economicamente sem trazer grandes ônus ao ambiente e a sua qualidade de vida.

\section{REFERÊNCIA}

AB'SABER, A. N. Contribuições à geomorfologia do Estado do Maranhão. Notícias Geomorfológicas, v.3, n. 5, p. 35-44, abr. 1960.

BARBOSA, G. V.; PINTO, M. N.. Geomorfologia da folha SA 23 - São Luís e parte da folha SA 24 Fortaleza. In: Levantamento de recursos naturais: geologia, geomorfologia, solo, vegetação e uso potencial da terra. Rio de Janeiro: MME, 1973. v.3.

BRANDÃO, V. S.; PRUSKI, F. F.; SILVA, D. D. Infiltração da água no solo. Viçosa: UFV, 2002. 98 p.

CAVALCANTI JUNIOR, F.A. Infiltração de água no solo da sub-bacia do Rio Maracanã, São Luís - Ma. 2011. 46f. Monografia (Graduação em Geografia) - Universidade Federal do Maranhão, São Luis, 2011.

CEDERGREN, H. R. Seepage, drainage and flow nets. John Willey and New York: Sons, 1989.

CYSNE, A. L. N. Análise ambiental e de uso e ocupação do solo da Microbacia do Rio Maracanã, São Luís-Ma. 2011. 71f. Monografia (Graduação em Geografia) - Universidade Federal do Maranhão, São Luís, 2011.

MINISTÉRIO DO EXÉRCITO. Departamento de Ciência e Tecnologia. Diretoria de Serviço
Geográfico. Mapa planialtimétrico, folhas 30 , 31, 38 e 39, escala 1:10.000. São Luís, 1980.

EMPRESA BRASILEIRA DE PESQUISA

AGROPECUÁRIA. Levantamento exploratório: reconhecimento de solos do Estado do Maranhão - escala 1: 1.000.000. Brasília,DF: Embrapa, 1986.

INSTITUTO NACIONAL DE METEOROLOGIA. Dados climatológicos do Maranhão. Disponível em: <http://www.inmet.gov.br>. Acesso em: 5 nov. 2011.

KARMANN, I. Ciclo da água, água subterrânea e sua ação geológica. In: TEIXEIRA, W. et al. (Org.) Decifrando a terra, 2.ed., São Paulo: Oficina de textos, 2003. p. 114-138.

LEPSCH, I. F. Formação e conservação dos solos. São Paulo: Oficina de Textos, 2002.

LIBARDI, P. L. Dinâmica da água no solo. Piracicaba: ESALQ/USP, 1980.

MARANHÃO. Secretaria de Estado do Meio Ambiente e Recursos Hídricos. Programa Estadual de Gerenciamento Costeiro. Macrozoneamento do Golfão Maranhense. Diagnóstico ambiental da microrregião da aglomeração urbana de São Luís e dos municípios de Alcântara, Bacabeira e Rosário. São Luís, 1998. Apostila SEMA/MMA/PNMA: estudo de Pedologia/ Cobertura Vegetal.

NUGEO. Núcleo Geoambiental. Levantamento de Solo do Estado do Maranhão, 2009.

OLIVEIRA, L. R. C. Uso, manejo, conservação e importância sócioeconômica da juçara (euterpe oleracea mart.; palmae) na ilha de São Luís, Maranhão. Dissertação (Mestrado) - Programa de Pós-Graduação em Agroecologia, Universidade Estadual do Maranhão, São Luís, 2003.

PEREIRA, E.D. (Org.) Recuperação das áreas degradadas de recarga e descarga do aquífero barreiras da sub-bacia do Rio Maracanã.

2012. 150 p. Relatório final de pesquisa. São Luís: convênio CNPQ/UFMA.

PEREIRA, E. D. Avaliação da vulnerabilidade natural à contaminação do solo e aquífero do reservatório do Batatã - São Luís (MA). 2006. Tese (Doutorado) - Universidade Estadual Paulista, Rio Claro, 2006.

RADCLIFFE, D. E.; SIMUNEK, J. Soil physics with hydrus: modeling and applications. Florida: CRC Press, 2010.

REICHARDT, K. A água em sistemas agrícolas. São Paulo: Manole, 1990.

RODRIGUES, T. L. N. et al. (Org.) Programa de levantamentos geológicos básicos do Brasil: São Luís, folha SA-23-2-A, Cururupu folha SA-23-X-C, escala 1: 250.000, Brasília, DF: CPRM, 1994. 185 p.

SILVA, Q. D. Mapeamento geomorfológico da Ilha do Maranhão.2012. 246f. Tese 
(Doutorado) Universidade Estadual Paulista, Presidente Prudente, 2012.

STRAHLER, A. N. Climate and their

classification. Physical Geography: 2. ed. New York: John Wiley, 1960.
UNIVERSIDADE FEDERAL DO MARANHÃO.

Estudo de impacto Ambiental/Relatório de impacto ambiental EIA-RIMA da Refinaria

PREMIUM I. Bacabeira - Maranhão, 2009. v.2. 